\title{
The Ordinary is Extraordinary; The Wonder of the Mundane Physical World
}

\author{
CHARLES TALIAFERRO \\ St. Olaf College, USA \\ taliafer@stolaf.edu
}

\begin{abstract}
Philip Kitcher and other secular naturalists assert that we have a problem-free concept of the "mundane physical world" and use the idea of our familiar material world to critique those who recognize a transcendent reality as in theism. It is argued that the naturalist's concept of the world faces problems involving the primacy of the mental, normativity, sensations and consciousness, and contemporary science. A closing section suggests, contra secular naturalism, that our experience of the mundane world can be suffused with a sense of the transcendent, as we find in Tolstoy's Anna Karenina. This conclusion is supported by reference to other work.
\end{abstract}

Keywords: Philip Kitcher; secular naturalism; the transcendent; normatively; sensations; consciousness; the mental; the physical.

Philip Kitcher is representative of philosophers who believe we have a problem-free understanding of the world without any of the troubling features of the transcendent. "The core of secular doubt is skepticism about anything 'transcendent'” (Kitcher 2014, 3). Kitcher proposes that all historical claims about the transcendent are evidentially impoverished compared to "the mundane world": "Religions are distinguished by their invocation of something beyond the mundane physical world, and they offer claims about this transcendent” (Kitcher 2014, 2). Mario De Caro and Alberto Yol- 
tolini likewise assume that the "familiar natural world" is non-mysterious and possesses none of the obscurity of the supernatural: "By 'supernaturalism' I mean the invocation of an agent or force that somehow stands outside the familiar natural world and whose doings cannot be understood as part of it" (De Caro and Voltolili 2010, 71). In a recent, excellent book on contemporary naturalism, Fiona Ellis documents the many ways in which philosophers have insisted on a trouble-free understanding of the natural world, compared to which God, objective, moral properties, and normativity are "irreducibly odd," "very weird," "spookingly different," "too spooky," "irredeemingly weird," "alien," occult and magical," a "region of darkness," and a "super-addition to the world" (Ellis 2014, 51, 58, 63, 74, 82, 86, 88).

In this essay, I contend that we have abundant reasons to think that the world as it appears to us is far from supporting a problem free-metaphysics, epistemology, and theory of values. Reflection on familiar, "mundane" aspects of the world as we experience it, gives rise, instead, to serious questions that welcome some response that involves the transcendent. In some respects, I will be drawing attention to areas with which readers should be philosophically familiar. But readers rarely consider these areas as an accumulation of factors that both makes an appeal to the mundane and makes the familiar world problematic. Specifically, I draw attention to the problem of how to understand the mundane world in reference to normativity, sensory qualities and consciousness, and contemporary physics. Most importantly, the first point to appreciate is that we often fail to appreciate the role of concepts and the mental in even thinking at all about the physical world. In a concluding section, I suggest that among the many reasons for the persistent appeal to the transcendent is the fact that many persons seem to experience the transcendent through the "mundane world," due also to an appreciation of the ostensible contingency of the mundane world.

\section{The very idea of the physical world}

Although the following claim may seem trivially true, it is radically under appreciated: the idea that we live in the physical world is itself an idea. 
Our access to physical and material things, i.e., events, objects, processes, is invariably and inescapably by way of what is classified as the mental. This is by way of any number of different terms (the terms ideas, concepts, beliefs, theories, frameworks, images - as in the scientific or manifest images). An example of a brazen, unapologetic statement of materialism that seems (in the mind of its author,) to eschew the mental is found in the work of Daniel Dennett:

The prevailing wisdom, variously expressed and argued for, is materialism: there is only one sort of stuff, namely matter -the physical stuff of physics, chemistry, and physiology -and the mind is somehow nothing but a physical phenomenon. In short, the mind is the brain. According to materialists, we can (in principle) account for every mental phenomenon using the same physical principles, laws, and raw materials that suffice to explain radioactivity, continental drift, photosynthesis, reproduction, nutrition, and growth (Dennett 2001, 33).

Note what this often-cited passage seems to require us to believe in: that there is such a thing as wisdom, and this wisdom is expressed and argued for. Presumably, arguments essentially involve providing reasons for accepting some positions and rejecting others. In the book in which this passage appears, Consciousness Explained, one of the principle objectives is to demonstrate why dualism in philosophy of mind should be rejected. However, note how important it is that Dennett's enterprise seems to commit us all to believing that authors exist as substantial individual beings who are selfaware and aware of other persons who act intentionally to bring about real changes, in the beliefs of other persons and in their actions. The passage also commits us all to believing that we possess ideas or concepts about the mental, the concept of materialism, matter, explanations that are exclusive ("nothing but"), and a concept of the brain. We also must acknowledge all that goes along with physics, chemistry, and physiology. Presumably these three forms of inquiry are inconceivable without there being persons who are scientists who make observations, engage in criticism, theory-construction. The scientists are conscious self-aware beings with the full repertoire of sensations, thoughts, and so on. I propose that it is absurd to think one 
can have a clearer grasp of anything Dennett refers to in the passage than one can have of the concept (or idea or thought) of what Dennett refers to.

The nature of physics, as a practice, is not something you can have a more clear grasp about than you can have a clear grasp of the concept of physics and the multitude of concepts of all that constitutes and is involved in physics as a practice. Moreover, explanations of the kind that Dennett invokes - radioactivity, continental drift, photosynthesis, reproduction, nutrition, and growth-all require a certain grasp and reliance on complex mental activity. All the extant theories of causation and explanation of whether they appeal to laws of nature, primitive or basic causal powers, or the laws of nature or counterfactuals, all invariably involve appeal to our ideas (or concepts or beliefs or thoughts) about causation, basic causal powers or the laws of nature or counterfactuals. So, where and what are ideas, thoughts, beliefs, and so on? Do they take up space in the same fashion that radioactivity or continental drift take up the space they do?

I am not, on this occasion, offering a sustained case for dualism (see Goetz and Taliaferro 2011). I am merely drawing attention to how even referring to the mundane physical world involves recognizing the reality of thoughts, ideas, concepts and these do not have about them a matter of fact, common sense, and obvious place philosophically. It is sufficient at this stage of this essay to maintain that while philosophers like Dennett and Kitcher presume that we have a clear grasp of that which is physical, this presumption seems challenged by the thesis that we have, and necessarily have, a clearer grasp of that which is mental than that which is physical, even if it turns out that what we call the mental turns out to be that which we call the physical.

To reinforce this point, consider one of the crudest expressions of materialism in print: "If you can't kick it, or at least spray it, you should treat it with some suspicion" (Dupre 2004, 38). Anticipating the material in the next session, I suggest that the activity of kicking or spraying is not possible without sensations and consciousness. It is also not conceivable without intentions and having the ideas or concepts of kicking, spraying, and suspicion. Thus, how would one go about kicking or spraying ideas of 
concepts? The same is true about beliefs and doubts. Presumably, to be suspicious involves doubting some beliefs or thoughts or ideas. Let us now turn to other areas of the supposedly mundane and familiar physical world that cries out for serious philosophical attention.

\section{Normativity}

While there are naturalists who regard normativity as "weird," they customarily do so on the basis of reasons, as we have seen in the passage cited from Dennett's Consciousness Explained. A problem arises, however, when we take note that "radioactivity, continental drift, photosynthesis, reproduction, nutrition, and growth" do not involve processes of reasoning, or any reasons. One continent does not drift to the other on the basis of an argument. If the criterion for a satisfactory account of mind is limited to the same principles that explain radioactivity etc., then the account must not involve any irreducible appeal to reasoning. That is, accounts of reasoning must be accounted for in terms that do not involve any reasoning. I propose and have argued elsewhere (see Taliaferro 1994, and Goetz and Taliaferro 2011) that explaining reasoning in terms that eliminate reasoning as an irreducible element undermines the very phenomenon of reasoning itself. If asked what is the smallest perfect number, I reply 6 because 6 is the smallest number equal to the sum of its divisors, including 1 , but not including $6(1+2+3=6)$. A calculating machine can also be programmed to generate the number 6 when asked to identify the smallest perfect number, but no one thinks that a very primitive calculating machine thinks or is engaged in reasoning of any kind whatsoever. Controversy emerges with highly sophisticated machines, but the controversy is usually a matter of wondering whether a machine can develop mental powers not whether mental powers can be eliminated. Dennett's appeal to machine intelligence, incidentally, provides us with confirmation that he is an eliminativist with respect to the mental (see Taliaferro and Evans 2013).

Fiona Ellis rightly notes how the evidence of normativity in our reasoning about matters in general, and in ethics in particular, provides good 
reason for thinking there is something that transcends what is apparent to us in the physical and social sciences. She puts this point modestly:

The notion of normativity is hardly perspicuous and, in a moral context, has tended to go hand in hand with talk of the special authority or "binding force" of morality - it is said to be "inescapable" in some special way. We cannot assume the authority of such talk, nor that it poses an intractable difficulty for the scientist. However, it certainly seems amenable to the idea that there is a source of value that comes to us from without, and it seems plausible to suppose that this source grants just the kind of intrinsic normative element which is said to be problematic by the lights of our current social scientist. (Ellis 2014, 28).

Even if normativity can be eliminated or reduced to secular naturalism, it certainly provides us with a reason for thinking that an appeal to a common sense, familiar, mundane physical world is neither straightforward nor simple. The same is true, in my view, when it comes to taking seriously sensory experience and consciousness itself.

\section{Sensations and Consciousness}

We first have the age-old questions about what are often called secondary properties: does the mundane physical world smell? Does it make sounds? Does it taste a certain way? Does it feel hot or cold? And once we have sensations in our ontology, we face the problems facing the identity theory (the Mary argument or knowledge arguments) defended recently to great effect by Richard Fummerton in Knowledge, Thought, and the Case for Dualism. Fummerton relentlessly highlights the overwhelmingly evident fact of the matter that we are acquainted with sensations or that we undergo sensory states and these are not identically the same thing as the brain states identified by materialists. "Acquaintance is a real relation and its obtaining is contemporaneous with the existence of its object. One can't use a razor [as in Ockham's razor] to slice away from one's ontology one's searing pain" (Fummerton 2013, 247). 
The extensive literature that currently defends the irreducible, evident reality of consciousness and its non-identity, with what materialists identify as the physical world, is tantamount to evidence that Kitcher's and others' references a problem-free understanding of the physical world is not warranted. (See work by Mark Baker, George Bealer, Lawrence Bonjour, Matthew Dickerson, Stewart Goetz, H.L.A. Hart, William Hasker, Robert Koons, Angus Menuge, Daniel Robinson, Richard Swinburne, Charles Taliaferro, Peter Unger, Dean Zimmerman).

Now consider one other obstacle to thinking that an appeal to the familiar, mundane physical world, versus the transcendent, is problem-free.

\section{Contemporary Physics}

It was fairly commonplace in the $19^{\text {th }}$ and early $20^{\text {th }}$ centuries to think that materialism is in concert with an appeal to the physical sciences. Subsequent science, however, seems to expose us to a world that seems to shatter a straightforward, simple understanding of what it is to be physical. Noam Chomsky contends that we currently lack consensus on what counts as physical:

What is the concept of body that finally emerged? The answer is that there is no clear and definite concept of body. If the best theory of the material world that we can construct includes a variety of forces, particles that have no mass, and other entities that would have been offensive to the "scientific common sense" of the Cartesians, then so be it: We conclude that these are properties of the physical world, the world of body. The conclusions are tentative, as befits empirical hypotheses, but are not subject to criticism because they transcend some a priori conception of body. There is no longer any definite conception of body. Rather, the material world is whatever we discover it to be, with whatever properties it must be assumed to have for the purposes of explanatory theory. (Chomsky 1988, 144)

Anthony Kenny, perhaps the greatest living historian of philosophy, takes note of how contemporary science has removed our confidence in common sense materialism. 
At one time it seemed as if a robust and substantive naturalism could be easily stated. This was a conception that thought of the world as being made up of solid, inert, impenetrable and conserved matter - a matter that interacts deterministically and through contact. But twentieth-century physics posited entities and interactions that did not fit the materialist characterization of reality, and which took science far away from a world of solid, inert, massy material atoms. (Kenny 2013)

In this section, I rely on three other authorities as providing reason for thinking that Kitcher et al, are not supported by current science in thinking we have a problem-free concept of the mundane, familiar physical world. Here is Bitbol: 'Material bodies are no longer the basic objects of physics... Ironically, the notion of material body motivated the very research that eventually dissolved it." (Bitbol) And from Crane and Mellor: "The 'matter' of modern physics is not at all solid, or inert, or impenetrable, or conserved, and it interacts indeterministically and arguably sometimes at a distance. Faced with these discoveries, modern materialism's modern descendants have understandably lost their metaphysical nerve." (Crane, Mellor 1990, 186) Finally, in An Outline of Philosophy, Bertrand Russell observes: "Matter has become as ghostly as anything in a spiritual séance” (Russell 1927, 78).

\section{Religious Experience Through and In the Midst of a Contingent Cosmos}

It will be too much of a burden to attach to this short essay an extensive account of theism as a coherent, even cogent alternative to secular naturalism. Stewart Goetz and I have argued for the implausibility of naturalism in the book Naturalism (2008) and the failure of the critique of theism advanced by naturalists. And I have defended the evidential power of appealing to the transcendent, theism in particular, in various places, including "In Defense of the Numinous." I shall appeal, instead, in this final section to a literary treatment of how the experience of the mundane, physical world can provide a setting in which the experience of God is not 
"irreducibly odd," “very weird," "spookingly different," "too spooky," "irredeemingly weird," "alien," occult and magical," a "region of darkness," and a "super-addition to the world."

Consider the character Levin in Tolstoy's classic Anna Karenina. Levin is a wealthy landowner who is haunted by death and the contingency of his life and the world itself. What is the meaning of life? He marries and seeks refuge in gambling and his searching for life's meaning seems at first hopeless. He finds the mundane, familiar world profoundly unsatisfying and absurd. Still, near the end of the novel, he undergoes a transformation:

Suddenly, in the midst of his toil, without understanding what it was or whence it came, he felt a pleasant sensation of chill on his hot, moist shoulders. He glanced at the sky in the interval for whetting the scythes. A heavy, lowering storm cloud had blown up, and big raindrops were falling. Some of the peasants went to their coats and put them on; others-just like Levin himself-merely shrugged their shoulders, enjoying the pleasant coolness of it.

Another row, and yet another row, followed-long rows and short rows, with good grass and with poor grass. Levin lost all sense of time, and could not have told whether it was late or early now. A change began to come over his work, which gave him immense satisfaction. In the midst of his toil there were moments during which he forgot what he was doing, and it came all easy to him, and at those same moments his row was almost as smooth and well cut as Tit's. But so soon as he recollected what he was doing, and began trying to do better, he was at once conscious of all the difficulty of his task, and the row was badly mown. (Part III, Ch. IV)

Levin meets an old peasant who does not forget God. Levin asks him what it is like to not forget God. Levin replies: "Why, that's plain enough. It's living rightly, in God's way." (Part 8, Ch. XI)

Levin finds his experience of the mundane, physical world hallowed by a sense of the presence of the transcendent God, a transcendent God who is felt to be immanent. This is the very opposite of living as though an object of our belief is suspicious if you cannot kick it or spray it; it is quite distant from adopting a philosophy that calls into questions whether normativ- 
ity in general, ethics in particular, persons or consciousness or sensory experience do not exist as fundamental features of our world. The kind of spirituality that emerges with Levin constitutes a powerful challenge to a confident secular naturalism that claims to have a better grounding when it comes to offering a description and account of ourselves and the world we find ourselves in.

\section{References}

Bitbol, Michel. 2007. “A More Radical Critique of Materialism a Dialogue with Bas van Fraassen About Matter, Empiricism and Transcendentalism.” Images of Empiricism, Essays on Science and Stances, with a Reply from Bas van Fraassen, Oxford University Press.

Chomsky, Noam. Language and Problems of Knowledge. Cambridge: MIT Press, 1988.

Crane, Tim and Mellor, D. H. “There is No Question of Physicalism” Mind, Oxford University Press, 1990.

De Caro, Mario and Alberto Voltolini. “Is Naturalism Possible?” Naturalism and Normativity, ed. De Caro and David Macarthur. New York: Columbia University Press, 2010), 71-75.

Dennett, Daniel. Consciousness Explained. Cambridge: MIT Press, 2001).

Dupre, John. “The Miracle of Monism,” Naturalism in Question, ed by Mario De Caro and David Macarthur. Cambridge: Harvard University, 2004.

Ellis, Fiona. God, Value, and Nature. Oxford: Oxford University Press, 2014.

Fummerton, Richard. Knowledge, Thought, and the Case for Dualism. Cambridge: Cambridge University Press, 2013.

Goetz, Stewart and Charles Taliaferro. A Brief History of the Soul. Oxford: Wiley Blackwell, 2011.

Goetz, Stewart and Charles Taliaferro. Naturalism. Grand Rapids: Eerdmanns, 2008) Kenny, Anthony. “Mere C.S. Lewis.” Times Literary Supplement, June 19, 2013.

Kitcher, Philip. Life After Faith. Yale: Yale University Press, 2014.

Russell, Bertrand. An Outline of Philosophy. London: Routledge Press, 1927.

Taliaferro, Charles. Consciousness and the Mind of God. Cambridge: Cambridge University Press, 2014.

- "In Defense of the Numinous." Philosophy and the Christian Worldview ed. by David Werther and Mark Linville. London: Continuum, 2012.

Taliaferro, Charles and Jil Evans. The Image in Mind. London: Continuum, 2013. Tolstoy, Anna Karenina, 1877. 